\title{
Crimen de feminicidio y prevención de la tortura: a propósito de la sentencia de la Corte Interamericana de Derechos Humanos en el caso del "Campo Algodonero"
}

Fernando M. Marin̄o*

- Doctor en Derecho por las Universidades de Bologna y Complutense de Madrid. Es diplomado en Derecho Internacional por la Academia de Derecho Internacional de La Haya. Desde 1990, es catedrático de Derecho Internacional Público en la Universidad Carlos III de Madrid, donde fundó el Instituto Francisco de Vitoria de Estudios Internacionales y Europeos que ha dirigido entre los afios 1994 y 2010.

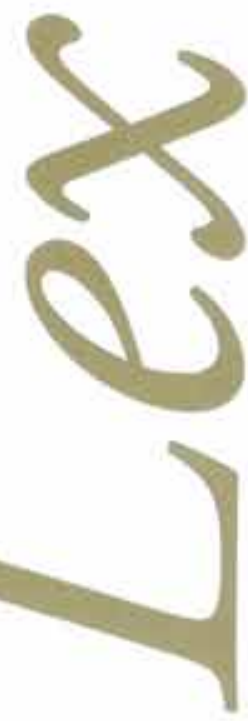



T a sentencia dictada por la Corte Interamericana de Derechos Humanos en el caso de "Campo Algodonero" en el 2009 condenó al Estado mexicano por violación de diferentes artículos de la Convención de San José. La decisión merece una especial atención, porque se ocupa de cuáles son las obligaciones de un Estado Parte en materia de prevención y protección de derechos fundamentales, especialmente en un contexto social como el de Ciudad de Juárez, caracterizado por una violencia estructural contra las mujeres. La violencia alcanza la calificación de feminicidio y exige del Estado toda una serie de medidas que erradiquen la cultura de la discriminación y del desprecio social por las mujeres. Tortura y feminicidio aparecen estrechamente vinculados en la práctica. Ese avance jurisprudencial tiene paralelismo con ciertas decisiones del Tribunal Europeo de derechos humanos que lucha por reprimir la violencia sistémica contra la mujer, existente, como violencia doméstica, en determinados Estados europeos.

Para el ordenamiento jurídico internacional, la promoción y protección de los derechos humanos fundamentales constituye un verdadero programa constitucional que ha encontrado su formulación, dentro de él, como principio fundamental. En efecto, sobre la base de la práctica internacional y como expresión privilegiada de la conciencia jurídica de la humanidad, organizada como Comunidad Internacional, es posible afirmar la vigencia de un principio constitucional o "fundamental" del Derecho Internacional que impone a los Estados y demás sujetos internacionales, según su diferente naturaleza jurídica, deberes de respeto y protección, de prevención y sanción, a su violación, y de cooperación para su realización, a tales derechos. De este modo, determinadas normas jurídicas internacionales, adoptadas y aplicadas en la práctica como desarrollos de dicho principio, imponen obligaciones concretas de comportamiento y/o de resultado, positivas y/o negativas, adquiriendo, en ciertos casos, el carácter de normas imperativas de Derecho Internacional general. ${ }^{1}$

1. Este artículo se basa en el trabajo presentado al Libro Homenaje al profesor Oriol Casanovas (Barcelona 2010, en prensa). 
Sin debatir aquí la relevancia de la distinción entre principio constitucional, principio general del Derecho y norma jurídica concreta, podemos admitir, con base en la práctica que está en vigor en el cuerpo del Derecho Internacional de los derechos humanos, ciertos principios generales válidos para todo ese ámbito normativo.

Los más relevantes de entre esos principios son los siguientes: el principio de dignidad de la persona; el principio de humanidad; el de universalidad, indivisibilidad e interdependencia de todos los derechos humanos; el de igualdad y no discriminación, en particular el de igualdad entre hombre y mujer; el de inderogabilidad absoluta de un núcleo duro de Derechos Humanos fundamentales; el de satisfacción de las necesidades básicas de carácter económico, social y cultural de toda persona; el de protección particular de personas y colectivos vulnerables, según su naturaleza y situación específicas, (niños, mujeres, personas con discapacidad, víctimas de conflictos armados, refugiados, indígenas); el de aplicación del instrumento jurídico más protector; el de responsabilidad individual internacional penal por "crímenes internacionales"; y el de responsabilidad internacional de los Estados frente a la Comunidad Internacional por violaciones graves (generalizadas y/o sistemáticas) de Derechos Fundamentales.

En particular, la constitucionalidad internacional de la perspectiva de género, es decir, de la protección particularmente reforzada de los derechos de la mujer, entendida como un elemento del programa constitucional del más elevado nivel normativo en todo el ancho campo del ordenamiento internacional, se abrió camino en la Comunidad Internacional a través de un proceso que quizá tenga su hito histórico fundacional más característico en las resoluciones y recomendaciones de la Conferencia de Pekín de $1995 .{ }^{2}$ Dentro de esta perspectiva, cada derecho fundamental puede aparecer lesionado y es especialmente protegido en perspectiva de género, puesto que el colectivo de mujeres puede encontrarse, y se encuentra de hecho en determinados Estados, en riesgo agravado o en situación de vulnerabilidad particular.

Así, un caso paradigmático es el de la protección del derecho fundamental a no ser sometido a torturas u otros tratos o penas crueles inhumanos o degradantes y, más en general, a cualquier forma de violencia. El complejo de normas internacionales, que impone obligaciones y atribuye derechos en materia de lucha contra la tortura y los demás tratos inhumanos en el seno del ordenamiento internacional, tiene un fundamento constitucional "reforzado", puesto que la prohibición internacional de la tortura (y por extensión de los demás tratos inhumanos) es absolutamente inderogable.

Puede consultarse el aún útil volumen, MARIÑO MENÉNDEZ, F.M. (edit.), La protección internacional de los derechos de la mujer tras la Conferencia de Pekin de 1995. Madrid: BOE y Universidad Carlos III, 1997. 
Así, la prevención y represión de la violencia contra la mujer ha adquirido una especificidad jurídica internacional propia, debido al citado rango constitucional de la perspectiva de género y a la imperatividad de normas concretas o principios generales que la desarrollan. A ello, están contribuyendo particularmente los desarrollos impulsados por la práctica del Derecho Internacional de los derechos humanos en el sistema regional interamericano y europeo.

La sentencia a que aquí se hace referencia, asumiendo tendencias y calificaciones previas, alumbra la noción de "feminicidio" que está llamado a concretar un crimen internacional autónomo (como crimen internacional individual) o bien a dar forma a un crimen contra la Humanidad, internacionalmente atribuible a un Estado y a uno o más individuos. Al mismo tiempo, la práctica señalada origina una constelación de normas internacionales dirigidas a que los Estados (y en su caso otros sujetos del ordenamiento jurídico internacional) prevengan la comisión de tal crimen, sancionen a sus perpetradores y, en definitiva, eliminen la impunidad y erradiquen tal práctica criminal.

Me parece importante destacar aquí que quien cabalmente introdujo en la doctrina española contemporánea la referencia a la perspectiva constitucional en el Derecho Internacional fue el profesor Manuel Diez de Velasco quien, en su primer manual, presentó con rigor no ya la noción de Comunidad Internacional sino los análisis "constitucionalistas" de la mejor doctrina iusinternacionalista italiana de las décadas de 1950 y 1960 . La adición a ésta de las normas de Ius Cogens fue introducida (aparte, los trabajos del maestro D. Adolfo Miaja) por el profesor Juan Antonio Carrillo y la profesora Elisa Pérez Vera, teniendo ya como referente de Derecho Internacional positivo los artículos 53 y 64 de la Convención de Viena sobre el Derecho de los Tratados de 1969. ${ }^{3}$

El efecto sistematizador y "unitario" de esas dos perspectivas impulsaron progresos significativos de la doctrina iusinternacionalista española posterior a la guerra civil de 1936-39. Así, la introducción del concepto metodológico de sistema jurídico y los análisis sistemáticos fueron, a mi juicio, llevados a cabo en cuanto al estudio contemporáneo del Derecho Internacional en la doctrina española, principalmente por Julio González Campos. ${ }^{4}$

3 CARRILlO SALCEDO, J. A. Soberanía del Estado y Derecho Internacional. Madrid: Tecnos, $2^{\text {a }}$ ed., 1976. Véase una última síntesis del pensamiento del profesor Carrillo en su discurso tras su investidura por la Universidad de Málaga como Doctor Honoris causa (con Laudatio del profesor A. Rodríguez Carrión, prematuramente fallecido en: Universidad de Málaga. Ceremonial para la investidura como Doctor Honoris causa del Excmo. Profesor. Dr. Juan Antonio Carrillo. Málaga, 2009, en especial p.57 ss. De la Profesora E. Pérez Vera, véase particularmente su antiguo y valioso trabajo, Naciones Unidas y los principios de la coexistencia pacifica. Madrid: Tecnos, 1973.

4 Cf. los orígenes de la visión "sistemática" sobre el Derecho Internacional de J. González Campos, ante todo en: Lecciones del programa de Derecho Internacional Público. Universidad de Oviedo (curso 1976-77). La metodología se plasmó luego en el Curso de Derecho Internacional Público, obra objeto de sucesivas ediciones y realizada conjuntamente con los profesores L.I. Sánchez, recientemente fallecido, y Ma Paz Andrés. 
Por mi parte, junto con algún otro autor, adelanté en su día una propuesta para volver a utilizar la noción de Constitución -en mi caso, "Constitución material"- en los análisis del sistema de Derecho Internacional, siguiendo desde luego una línea que, después de la Segunda Guerra Mundial, abrió sobre todo H. Kelsen con su análisis de la Carta de Naciones Unidas y siguió, tan fructíferamente entre nosotros, la profesor Victoria Abellán ${ }^{5}$. El profesor Oriol Casanovas, sensible a las aportaciones de la mejor doctrina, dio puntual testimonio (como, a lo largo de los años, de tantas otras novedades científicas) de la reintroducción por la doctrina española de los análisis de sistema sobre el orden jurídico internacional ${ }^{6}$, luego convertidos casi en tópico por la doctrina de nuevas generaciones.

La Corte Interamericana de Derechos Humanos, en su reciente sentencia en el asunto del Campo Algodonero, afronta de modo directo varias cuestiones básicas relativas a la determinación del contenido del deber genérico de prevenir la violencia contra las mujeres $\mathrm{y}$, consecuentemente, de garantizar el cumplimiento de la prohibición de la tortura: prevenir la tortura, y las diferentes formas de su violación en una perspectiva de género. ${ }^{7}$ En efecto, la clave más característica de esta importante decisión reside en que en ella se trata de determinar responsabilidades estatales por muerte, privación de libertad y torturas, y otros tratos inhumanos perpetrados en un contexto social de violencia estructural contra las mujeres.

La lucha contra ese fenómeno de criminalidad específica, identificado particularmente en el área mexicana de Ciudad Juárez, así como contra la impunidad de sus responsables, ha exigido de la Corte un esfuerzo esclarecedor de interpretación y aplicación de principios y normas de Derecho Internacional de los derechos humanos que merece especial atención y, en cualquier caso, una bienvenida a cuore aperto de cuantos consideran que la promoción y protección de los derechos humanos de la mujer constituye, como se ha indicado, un verdadero programa constitucional del ordenamiento jurídico internacional. La sentencia de Campo Algodonero refuerza ciertamente la prohibición universal de la tortura y demás tratos inhumanos y su naturaleza imperativa, y adecúa sus perfiles a la protección de los derechos de la mujer.

5. Lo hice, sucintamente, en las tres ediciones $(1987,1989$ y 1990) de las Nociones de Derecho Internacional Público. Ed. del Secretariado de Publicaciones de la Universidad de Zaragoza. Posteriormente, en las cuatro ediciones de Derecho Internacional Público. Parte general: cfr. el capítulo $3^{\circ}$ de la cuarta edición. Madrid: Tecnos, 2005, p. 69-94. A mi juicio, el ius internacionalista italiano de posguerra, más rigurosamente sistemático en cuanto a dogmática jurídica se refiere, fue el Juez G. Morelli de quien aún se consultan con interés sus Nozioni di Diritto Internazionale. Padua, $7^{\text {a }}$ ed. 1967. No es necesario insistir aquí en la relevancia general del pensamiento de Santi Romano para la teoría general del ordenamiento jurídico, algo que ya hice en mi trabajo Situaciones juridicas subjetivas constitucionales en Derecho Internacional. CEBDI, Vol.III, 1999, p. 315-362.

6 Ver, por ejemplo, sus propias reflexiones generales dotadas del espíritu pedagógico que le ha caracterizado, en su curso Unidad y pluralismo en Derecho Internacional Público. CEBDI, Vol. II, 1998, p. 57 y ss.

7 Corte Interamericana de Derechos Humanos. Caso González y otras ("Campo Algodonero") vs. México. (Excepción preliminar, fondo, reparaciones y costas). Sentencia del 16 de noviembre de 2009. 
Recordaré que la Comisión Interamericana de Derechos Humanos presentó, ante la Corte, una demanda contra México el 4 de noviembre del 2007 relacionada con la supuesta responsabilidad de ese Estado por la desaparición y ulterior muerte de tres jóvenes (González, Herrera y Ramos), cuyos cuerpos habían sido encontrados en un campo algodonero de Ciudad Juárez el 6 de noviembre de 2001.

La demanda responsabilizaba al Estado (ver párrafo 2 de la sentencia) por la falta de medidas de protección a las víctimas, dos de las cuales eran menores de edad; por la falta de prevención de estos crímenes, pese al pleno conocimiento de la existencia de un patrón de violencia de género que había dejado centenares de mujeres y niñas asesinadas; por la falta de respuesta de las autoridades frente a la desaparición de las tres jóvenes; por la falta de la debida diligencia en la investigación de los asesinatos; así como por la denegación de justicia y la falta de reparación adecuada.

La Comisión solicitó a la Corte (ver el párrafo 3 de la sentencia) que declarase al Estado responsable por la violación de los derechos consagrados en los artículos 4 (Derecho a la vida), 5 (Derecho a la integridad personal), 8 (garantías judiciales), 19 (Derechos del Niño) y 25 (Protección judicial), de la Convención Americana sobre Derechos Humanos de 1969, en relación con las obligaciones establecidas en sus artículos 1.1 (Obligación de respetar los derechos) y 2 (Deber de adoptar disposiciones de Derecho interno); y el incumplimiento de las obligaciones que derivan del artículo 7 (único estimado aplicable en el caso por la Corte) de la Convención de Belém do Pará para prevenir, sancionar y erradicar la violencia contra la mujer, adoptada el 9 de junio de 1994 en el marco de la OEA. ${ }^{8}$

Esta Convención, indicó la Corte, tiene como efecto preciso, relevante en el contexto de la sentencia, imponer a los Estados parte una "obligación reforzada" para prevenir la violencia contra la mujer (párrafo 258). El itinerario expositivo de la sentencia sigue, con lógica rigurosa, determinados pasos. Al comenzar su tarea de juzgar, la Corte indica que la va a llevar a cabo analizando el cumplimiento de "las obligaciones de respeto, garantía y no discriminación" (párrafo 112 in fine).

8 El artículo 1 de esta Convención define, para sus efectos, como "violencia contra la mujer: "cualquier acción o conducta, basada en su género, que cause muerte, daño o sufrimiento físico, sexual o sicológico a la mujer, tanto en el ámbito público como en el privado". Según los párrafos b) y c) del citado artículo 7: "Los Estados Partes condenan todas las formas de violencia contra la mujer y convienen en adoptar, por todos los medios apropiados y sin dilaciones, políticas orientadas a prevenir, sancionar y erradicar dicha violencia y en llevar a cabo lo siguiente : ...b) actuar con la debida diligencia para prevenir, investigar y sancionar la violencia contra la mujer; c) incluir en su legislación interna normas penales, civiles y administrativas, así como las de otra naturaleza que sean necesarias para prevenir, sancionar y erradicar la violencia contra la mujer y adoptar las medidas administrativas apropiadas que sean del caso". 
El contenido de la demanda presentada y los hechos de contexto relativos a la violencia contra las mujeres en Ciudad Juárez, puestos de manifiesto por aquella y por todas la fuentes de información a disposición de la Corte, exigían de ésta un análisis de los antecedentes sobre los que diferentes mecanismos nacionales de vigilancia de los derechos humanos ya habían llamado "la atención de la comunidad internacional". Realiza la Corte, entonces, un estudio pormenorizado de los antecedentes contextuales del fenómeno de los homicidios de mujeres y de sus cifras en la zona indicada, de las características de las mujeres agredidas y de la existencia de un patrón de violencia sexual, en un elevado porcentaje de dichos actos de violencia, basado en el género. La Corte determinó que cabía tipificar cada uno de los hechos como "homicidio de mujer por razones de género", también conocido como "feminicidio" (párrafo 143), término éste que la Corte admite pero que decide no utilizar de nuevo en la sentencia.

Tras ese análisis contextual, la Corte concluyó en especial (párrafo 164) que consideraba altamente preocupante el hecho de que algunos de los crímenes parecían presentar altos grados de violencia, incluyendo violencia sexual, así como la sospecha de que, en general, su perpetración habría estado bajo la influencia de una cultura de discriminación contra la mujer. $\mathrm{Y}$, ante los alegatos de irregularidades en las investigaciones de los crímenes y en los procedimientos seguidos, así como de las actitudes discriminatorias de las autoridades y la falta generalizada de esclarecimiento de los crímenes, la Corte afirmó que "las respuestas ineficientes y las actitudes indiferentes documentadas en cuanto a la investigación" parecían haber permitido la perpetuación de la violencia contra la mujer en Ciudad Juárez. Precisamente, los crímenes cometidos con características de violencia sexual eran los que hasta 2005 presentaban mayores niveles de impunidad.

En un contexto así definido, la Corte analiza los hechos concretos relativos a la violencia empleada contra las tres víctimas. En primer lugar, indaga cuál fue la actuación de las autoridades estatales durante las primeras 72 horas transcurridas tras la desaparición de las jóvenes y, en particular, estudia la alegada falta de búsqueda de las víctimas. La Corte destaca, en efecto, que el Estado, que tiene en el caso la carga de la prueba y posee los elementos probatorios principales de su propia actividad, no había aportado elementos que probaran que hubiera actuado "más allá de diligencias rutinarias y formales" en la búsqueda de las víctimas que debía ser real y efectiva (párrafo 180).

El Estado no había demostrado haber realizado gestiones concretas y haber buscado, efectivamente, a las víctimas durante ese periodo. Más aún, como en su día ya había señalado la relatora de Naciones Unidas sobre la violencia contra la mujer y la Corte también admite, al parecer la policía de Ciudad Juárez no emprende por sistema acciones de búsqueda ni adopta 
ninguna otra medida preventiva. En el momento de recibir una denuncia de desaparición de una mujer, inexplicablemente suele esperar a que se confirme la comisión de un delito (párrafo 195). La Corte considera probado que existió, por lo menos, una indiferencia de los funcionarios estatales hacia los familiares de las víctimas y sus denuncias, fruto de la prevalencia entre ellos y, en su actividad, de un estereotipo de misoginia

De otra parte, aun habida cuenta de la ausencia de muchos elementos probatorios, fruto de las deficiencias de la investigación, todos los indicios indicaban que, en cuanto a la violencia efectivamente sufrida por las jóvenes, estas fueron sometidas, tras su secuestro, a graves sufrimientos sicológicos y a graves torturas físicas, incluso sexuales (párrafo 220). En consecuencia, la Corte afirma que las jóvenes fueron víctimas de "violencia contra la mujer" en el sentido del artículo 1 de la Convención de Belém do Pará y considera que los homicidios fueron cometidos "por razón de género", y estaban enmarcados en el reconocido contexto de violencia contra la mujer (párrafo 231).

La Corte afirma que no se había probado que la violencia contra las jóvenes hubiera sido directamente aplicada por agentes del Estado o por particulares con el consentimiento de aquellos? ${ }^{9}$. No había, pues, lugar a examinar la posible violación, por el Estado, de su obligación de "respetar" los derechos sustantivos de las víctimas que le impone con carácter general el artículo 1 de la Convención Americana ${ }^{10}$, aunque sean también obligaciones de Derecho Internacional general. En cambio, manteniéndose siempre en un terreno de obligaciones convencionales, puso todo su énfasis y esfuerzo en determinar la posible violación de las obligaciones de "garantía "de los derechos humanos violados sobre la base del deber genérico de su cumplimiento, establecido por el citado artículo 1. Analiza, así, si el Estado previno adecuadamente la desaparición, los vejámenes y la muerte de las tres víctimas y si investigó las mismas con la debida diligencia (conforme a los artículos 4,5 y 7 de la Convención Americana y el 7 de la de Belém). Asimismo, intenta determinar si permitió el acceso a la justicia de los

9. En tal caso, hubiera podido plantearse la relevancia in casu del artículo 11 del Proyecto de artículos sobre la responsabilidad del Estado por hechos ilícitos (Res. A.G. 56/83 de 12 de diciembre de 2001) relativo al "comportamiento que el Estado reconoce y adopta como propio". De otra parte, la definición de tortura contenida en el artículo 1 de la Convención contra la tortura y otros tratos o penas crueles, inhumanos o degradantes de 10 de diciembre de 1984 tipifica también, como se sabe, la tortura por "consentimiento o aquiescencia" del Estado a los actos agresores perpetrados por particulares. En cuanto a esta cuestión, la decisión del Comité contra la Tortura de Naciones Unidas que tiene carácter paradigmático es la adoptada en el asunto $n^{\circ}$ 161/200, Hajrizi Dzemajl et al. $v$. Yugoslavia de 21 noviembre de 2002. Ver el texto en: U.N. Selected decisions of the Committee against torture. Vol. I Nueva York y Ginebra, 2008, p. 78 ss.

10 El artículo 1 de la Convención de 1969 establece: "Los Estados Partes en esta Convención se comprometen a respetar los derechos y libertades reconocidos en ella y a garantizar su libre y pleno ejercicio a toda persona que esté sujeta a su jurisdicción, sin discriminación alguna por motivos de raza, color, sexo, idioma, religión, opiniones políticas o de cualquier otra índole, origen nacional o social, posición económica o cualquier otra condición social". 
familiares de las tres víctimas (artículos 8.1 y 25.1 en relación con los artículos 1.1. y 2 de la Convención Americana).

El deber genérico de garantía se concreta en obligaciones fundamentalmente positivas, es decir, obligaciones de medio o comportamiento. Estas consisten, en primer lugar, en la obligación de adoptar medidas dirigidas a crear las condiciones para evitar que se produzca la violación de derechos fundamentales, como el derecho a la vida, la integridad personal y la libertad personal; y, en segundo lugar, la de adoptar medidas que aseguren que las eventuales violaciones sean efectivamente consideradas y tratadas como un hecho ilícito susceptible de acarrear sanciones para quien las cometa, así como la obligación de indemnizar a las víctimas por sus consecuencias perjudiciales (párrafo 252). ${ }^{11}$

En el caso aquí examinado, las medidas preventivas tienen que ser "medidas integrales" si es que han de cumplir efectivamente con la "diligencia debida" (párr. 258). Se trata de una obligación "reforzada”, como se ha señalado, por el efecto de la Convención de Belém. En particular, el cumplimiento del deber de prevención "reforzado" debe examinarse en relación con las medidas tomadas antes de la desaparición de las víctimas y, luego, tras la desaparición y antes de la localización de los cuerpos sin vida.

En cuanto a lo primero, la Corte constata la violación de la obligación de prevención, puesto que no se adoptó una política general cuando, ya en 1998, se advirtió el patrón de violencia general contra la mujer ${ }^{12}$ : el Estado conocía perfectamente (o debía conocer) la situación de violencia estructural contra las mujeres. Pero además, constata la Corte, no hubo cumplimiento del deber de diligencia estricta frente a denuncias de desaparición de mujeres (párr. 281 y 283). Tampoco había actuado con la diligencia requerida para prevenir las agresiones y muerte de las víctimas: no hubo una respuesta inmediata y eficaz ante las denuncias. Por eso, la Corte afirma finalmente que el Estado había violado los derechos a la vida, integridad personal y libertad personal reconocidos en la Convención Americana en relación con la obligación general de garantía (art. 1.1.) y la obligación de adoptar disposiciones de derecho interno (art.2), así como la relación con el artículo 7 b) y c) de la Convención de Belém do Pará.

11 Esta doctrina general ha sido consolidada por jurisprudencia de la propia Corte en la decisión de casos anteriores, comenzando ya, en cierto modo, por su primera decisión en el Caso Velásquez Rodríguez vs. Honduras. Fondo Sentencia de 29 de julio de 1988. Serie C, no 4, pár. 166. Ver una última sentencia en el Caso Perozo y otros vs. Venezuela. Excepciones preliminares. Fondo. Reparaciones y Costas. Sentencia de 28 de enero de 2009. Serie C, nº 195, párr.149.

12 Cf. las observaciones del Juez Diego García Sayán en su voto concurrente a la sentencia, sobre todo en los párrafos 11 y 12 de la misma. 
En particular, como expresión concreta especialmente relevante del deber de prevención, la Corte recuerda los estándares internacionales ${ }^{13}$ bien precisados ya al respecto por su jurisprudencia y por jurisprudencia del Tribunal Europeo de Derechos Humanos ${ }^{14} \mathrm{y}$ añade que esos deberes tienen alcances adicionales cuando se trata de una mujer que sufre una muerte, maltrato o afectación a su libertad personal en el marco de un contexto general de violencia contra las mujeres (párrafo 293).

La Corte pasa a examinar, entonces, las diversas acciones tomadas por el Estado tras el hallazgo de los cuerpos sin vida, así como los procedimientos, a nivel interno, destinados a dilucidar los hechos ocurridos y a identificar a los responsables de las violaciones cometidas en perjuicio de las víctimas, habida cuenta de que el propio Estado había reconocido irregularidades cometidas en una primera etapa-entre 2001 y 2003. Estas, sin embargo, según el Estado parte, habrían sido subsanadas por actuaciones posteriores de modo que la responsabilidad internacional del Estado no podría plantearse.

La Corte llega a la conclusión de que el Estado incumplió con su deber de investigar y, con ello, su deber de garantizar los derechos a la vida, integridad personal y libertad, consagrados en los artículos 4.1, 5.1, 5.2 y 7.1 de la Convención Americana, en relación con artículos 1.1 y 2 de la misma y el artículo 7 b) y 7c) de la Convención de Belém. Asimismo, en relación con estos últimos artículos, violó también los derechos de acceso a la justicia y protección

13 La más autorizada expresión de los estándares internacionales en el Manual sobre la Prevención e Investigación Efectiva de Ejecuciones extrajudiciales, Arbitrarias y Sumarias de Naciones Unidas. Doc. E/ST/CSDHA/12(1991). (Protocolo de Minnesota). Cf. Asimismo los Principios relativos a la investigación y documentación eficaces de la tortura y otros tratos o penas crueles, inhumanas y degradantes (Protocolo de Estambul), anexo a la resolución 55/89 de la Asamblea General de 4 de diciembre de 2000.

14 Ver párrafo 292. En su voto concurrente el Juez Diego García Sayán desarrolla de modo especialmente destacable la utilidad y relevancia de la jurisprudencia del TEDH en este ámbito del deber general y las obligaciones concretas, in casu, de prevención de las violaciones de los derechos humanos. 
judicial (párrafo 389). ${ }^{15}$ El deber general de no discriminar ${ }^{16}$ a la mujer, contenido en el artículo 1.1 de la Convención Americana, afirma la Corte, es violado por la violencia estructural de género presente en las condiciones generales de la zona de Ciudad Juárez ("cultura de discriminación") y por la reacción insuficiente y estereotipada de las autoridades inmediatamente después de las denuncias de la comisión de los crímenes en este caso. El estereotipo de género, su creación y uso, se convierte así en una de las causas y consecuencias de la violencia de género contra mujer.

De ese modo, considera la Corte que, en el caso sub iudice, la violencia contra la mujer constituyó una forma de discriminación y el Estado Parte violó el deber de no discriminación, contenido en el artículo 1.1 de la Convención Americana, en relación con el deber de garantía de los derechos de las tres jóvenes a la vida, la integridad personal y la libertad personal, así como en relación con el derecho de acceso a la justicia (artículos 8.1. y 25.1) de la Convención, en perjuicio de los familiares de las víctimas.

Conviene, asimismo, recordar que la tortura se define en la Convención de 1984 de Naciones Unidas como un crimen que se comete para lograr ciertos fines, en especial, "por cualquier razón basada en cualquier tipo de discriminación".

Sin que ahora entremos aquí en otros aspectos que merecen la atención de la Corte, como el "hostigamiento" probado a familiares de las víctimas, en relación con las investigaciones del caso, cabe destacar que el dato de que dos de las tres jóvenes objeto de la violencia fueran

15. Merece la pena reproducir in extenso el párrafo 388 de la sentencia que resume el fundamento de la decisión, tras afirmar las Corte que el reconocimiento parcial de responsabilidad por México no había subsanado totalmente las falencias detectadas en la primera etapa de las investigaciones. "Las irregularidades en el manejo de evidencias, la alegada fabricación de culpables, el retraso en las investigaciones, la falta de líneas de investigación que tengan en cuenta el contexto de la violencia contra la mujer (...) y la inexistencia de investigaciones contra funcionarios público por su supuesta negligencia grave, vulneran el derecho de acceso a la justicia, a una protección judicial eficaz y el derecho de los familiares y de la sociedad a conocer la verdad de lo ocurrido. Además, denota un incumplimiento estatal de garantizar, a través de una investigación seria y adecuada, los derechos a la vida, integridad personal y libertad personal de las tres víctimas. Todo ello permite concluir que en el presente caso existe impunidad y que las medidas de derecho interno adoptadas han sido insuficientes para enfrentar las graves violaciones de derechos humanos ocurridas. El Estado no demostró haber adoptado normas o implementado las medidas necesarias, conforme al artículo 2 de la convención Americana y el artículo 7 c) de la Convención de Belém que permitieran a las autoridades ofrecer una investigación con la debida diligencia. Esta ineficacia judicial frente a caso individuales de violencia contra las mujeres propicia un ambiente de impunidad que facilita y promueve la repetición de los hechos de violencia en general y envía en mensaje según el cual la violencia contra las mujeres puede ser tolerada y aceptada como parte del diario vivir."

16 El concepto de discriminación contra la mujer se encuentra definido en el artículo 1 de la CEDAW de 18 de diciembre de 1979. Cf. también Comité de la CEDAW. Recomendación General n 19: La violencia contra la mujer. U.N. Doc. HRI/GEN/Rev.1 (1994) 
menores de edad es objeto especial de atención en la sentencia de la Corte para destacar la mayor gravedad, si cabe, de los hechos en relación con la existencia, en el Derecho Internacional, de un deber de protección reforzada de dichas personas vulnerables, particularmente con base en las normas generales de la Convención sobre Derechos del Niño de 1989 y, específicamente, la base del artículo 19 de la Convención Americana (párrafos 403 a 411).

La Corte afirma categóricamente que la exigencia jurídica de que se repare "integralmente" todo el daño causado adopta modalidades especiales en el presente caso. Se trata, ciertamente, de restablecer la situación anterior a los hechos, eliminar los efectos que la violación de las obligaciones produjo e indemnizar por los daños causados.

Sin embargo, hay que tener en cuenta que los hechos se enmarcan en una situación de "discriminación estructural" y, por ello, las reparaciones deben tener "una vocación transformadora de tal situación": se trata no sólo de "restituir" sino de "corregir". Así, pues, las medidas de reparación, además de reparar proporcionalmente los daños materiales e inmateriales y restablecer en lo posible a las víctimas en la situación anterior "en aquello en que no se interfiera con del deber de no discriminar", se deben orientar a "identificar y eliminar" los factores causales de discriminación y deben adoptarse desde "una perspectiva de género" tomando en cuenta los impactos diferenciados que la violencia causa en hombre y en mujeres (párrafos 450 y 451).

En largos razonamientos, se desarrolla así el contenido de la obligación reparadora de investigar los hechos "en perspectiva de género" e identificar, juzgar y, en su caso, sancionar a los responsables de las violaciones; asimismo, se destaca las medidas de satisfacción, las garantías de no repetición y las indemnizaciones por daños materiales y daños inmateriales. En el párrafo 19 de sus "Puntos resolutivos", la Corte establece que el Estado deberá, en un plazo razonable, continuar con la estandarización de todos sus protocolos, manuales, criterios ministeriales de investigación, servicios periciales y de impartición de justicia utilizados para investigar todos los delitos que se relacionen con desapariciones, violencia sexual y homicidios de mujeres, conforme a los protocolos de Estambul y de Minnesota y otros estándares internacionales de búsqueda de personas desparecidas, con base en una perspectiva de género, acompañado de un informe anual cada tres años.

El voto concurrente de la jueza Cecilia Medina Quiroga es especialmente relevante desde la perspectiva de la lucha contra la impunidad de los torturadores de género, no solamente en la región americana sino en cualquier región del mundo. Desde la doctrina del Comité contra la tortura de Naciones unidas sobre la Convención de 1984, cuyo cumplimiento aquel vigila, me parece que nada hay que objetar a su afirmación de que el concepto de 
aquiescencia, empleado por el artículo 1 de tal Convención, es suficientemente amplio como para que, aplicado al Caso de Campo Algodonero, permitiera sostener que hubo aquiescencia del Estado Parte en la tortura de las tres jóvenes en el sentido de ser el Estado responsable de ella desde la doble, y complementaria, perspectiva del conocimiento, desde varios años antes, de la situación de violencia estructural de género existente en la zona de Ciudad Juárez y, más concretamente, por el hecho de que no se cumplieron las exigencias de búsqueda e investigación inmediatas, eficaces y adecuadas, conociéndose el riesgo de las desaparecidas a ser sometidas a tortura y muerte casi seguras.

Si los instrumentos jurídicos regionales, o incluso la práctica general de valor jurídico internacional, son en América más protectores, por menos estrictos, en lo que se refiere a atribuir a un Estado responsabilidad internacional por violación del derecho a no ser sometido a tortura, deben entonces prevalecer. Esta concepción, señala pertinentemente la jueza, inspira la propia Convención de 1984 que cede el paso a la "mejor" o "mayor" protección (artículo 1.2 y 16.2$)$.

Lógicamente, además, el ius cogens universal puede ser un ius cogens de mínimos, asimismo, otras normas regionales "más protectoras" sobre la misma materia pueden prevalecer sobre él en el sentido de profundizarlo; aunque no, claro está, en el de disminuirlo o derogarlo.

La Convención de 1984 contra la tortura fue adoptada en una época ya lejana en la que aún el Derecho Internacional de los derechos humanos no había alcanzado el grado de desarrollo actual, por ello su técnica es la de imponer obligaciones interestatales. En cambio, la dimensión de las obligaciones internacionales para con los propios ciudadanos u otras personas que se encuentren bajo la jurisdicción de un Estado Parte estuvo entonces menos desarrollada. El Comentario General n 2 adoptado en 2007 por el comité contra la tortura ha atendido en parte a esa fundamental evolución, incluyendo la perspectiva "constitucional de género" a la que se ha aludido anteriormente. ${ }^{17}$

Me interesa aquí realizar dos observaciones en esa dialéctica entre lo universal y lo regional en materia de protección de derechos humanos. En primer lugar, quiero decir que, en perspectiva universal, la propia prohibición de la tortura (universal, inderogable y de ius cogens) ha sido puesta en peligro por diferentes normas internas dictadas incluso por "democracias occidentales" tras los acontecimientos del 11 de septiembre de 2001. En segundo lugar, sostengo que el ancho mundo sigue incluyendo países cuya forma de luchar contra la

17 Cf.: HRI/GEN/1/Rev.9 (Vol.) de 27 de mayo de 2008, p. 124. 
violencia aplicada de modo discriminatorio a la mujer sigue adoleciendo de inadmisión de los estándares potencialmente universales. Pese a todo esto, podemos afirmar que es de ius cogens universal la obligación de no discriminar a la mujer en el goce de ningún derecho humano.

Una violencia estructural de género, como la existente en Ciudad Juárez, no combatida durante años, con la diligencia exigible internacionalmente por el Estado Parte, origina su responsabilidad internacional. Vista esa violencia "estructural" con ojos de exigencia de responsabilidad penal internacional de individuos, admitida la existencia de un ataque generalizado o sistemático contra la población civil practicado durante años por criminales tolerados por el Estado, podríamos encontrarnos ante hechos calificables de "crímenes contra la Humanidad".

Pero se trataría en ese caso, sobre todo, de responsabilidad penal internacional perseguible, desde luego y en primer lugar, ante los tribunales internos de cualquier Estado o ante un Tribunal Internacional penal competente. Aunque también es de exigencia de la responsabilidad internacional del Estado frente a otros Estados por crímenes de esa naturaleza. Dicho sea lo anterior en relación con la posibilidad de que tales "crímenes contra la Humanidad", o en su caso crímenes de guerra o genocidio, si tortura y muerte se subsumen en ellos, sean atribuidos a un Estado.

Mucho queda por hacer para que se conjuguen, armonicen o, por lo menos, se "compatibilicen" los regímenes de responsabilidad internacional individual por crímenes internacionales y de responsabilidad internacional del Estado por violaciones graves de derechos humanos fundamentales.

En cualquier caso, aunque ciertamente en relación con el crimen de genocidio, el Tribunal de La Haya haya destacado recientemente en su sentencia en el asunto de Asunto relativo a la aplicación de la Convención para la prevención y represión del crimen de genocidio (BosniaHerzegovina, Serbia y Montenegro) de 26 de febrero de 2007, hasta qué punto -por lo menos en cuestiones de atribución al Estados de crímenes internacionales cometidos por individuos- la doctrina de tribunales penales internacionales, como el caso del Tribunal Penal para la Antigua Yugoslavia, no es aceptable para la solución de litigios interestatales en los que se dirime la responsabilidad internacional de un Estado y en los que deben afrontarse problemas de atribución al Estado de actos de particulares (ver sobre todo los párrafos 388 a 404 de la sentencia).

La necesaria lucha universal en favor de los derechos de la mujer, previniendo su discriminación y desarrollando procedimientos y técnicas especiales de protección en 
perspectiva de género, nos permite afirmar que la sentencia en el Caso del Campo Algodonero puede ser considerada un hito relevante en un camino que, por su propia naturaleza, carece de límites temporales.

Así lo ha reconocido recientemente el Parlamento Europeo en su resolución de 5 de mayo de 2010 sobre la Estrategia de la Unión Europea para las relaciones con América latina, cuyo párrafo 34 establece literalmente:

"Saluda la reciente sentencia de la Corte Interamericana de Derechos Humanos sobre los feminicidios de Campo Algodonero en México, como precedente para toda la región; pide a los Gobiernos de la Unión Europea, América Latina y el Caribe que acojan la sentencia como guía para su futuro trabajo y que garanticen que acompañarán su firme condena de la violencia contra la mujeres con programas de protección, prevención y justicia y financiación adecuados; pide, asimismo, un decidido compromiso con la lucha contra la violencia de género en general, inversión adecuada en la salud reproductiva y en programas destinados a fomentar la igualdad de género, la educación sexual y el acceso a métodos de planificación familiar, según la Plataforma de Acción del ICPD (1994)”.

En la jurisprudencia más reciente del Tribunal Europeo de Derechos Humanos, parece que también comienza a consolidarse, de modo decidido, la afirmación de que la inacción de un Estado Parte frente a la persistencia de ciertas formas sistémicas de violencia contra la mujer, en particular de "violencia doméstica", constituye o puede constituir in casu una violación de los artículos 2, 3 y 8 de la Convención Europea de Derechos Humanos. Más en concreto, no sólo se afirma que ciertas formas de "violencia doméstica" pueden constituir tortura sino que la inacción del Estado, que no protege efectivamente a las mujeres frente a dicha violencia, incluso si no es "intencional", viola el principio de no discriminación del artículo $14 .^{18}$

Que los sistemas de protección regional de los Derechos Humanos más relevantes comiencen a dar sus frutos, en cuanto a la determinación de las obligaciones de los Estados Partes de adoptar todas las medidas necesarias para erradicar las estructuras sociales que originan y sustentan la violencia contra las mujeres considerada como una manifestación especialmente ominosa de su discriminación ilícita, constituye sin duda un avance muy relevante hacia la meta de lograr el respeto efectivo a la dignidad de cualquier mujer en igualdad completa con cualquier varón perteneciente a cualquier cultura.

18 Sentencia en el caso Opuz c. Turquía. App. No 33401/02 de 9 de junio de 2009. 
La ejecución de la sentencia en el Caso del Campo algodonero y las medidas que el Estado mexicano (altamente federalizado) obligatoriamente adopte al respecto van a abrir perspectivas nuevas en la determinación de las obligaciones internacionales positivas de prevención y protección frente a las más graves violaciones de los derechos humanos, así como en la exigencia de las responsabilidades subsiguientes a su comisión. La obligación internacional de prevenir la tortura "se refuerza" así sobre la base de todos los principios aplicables en el marco del Derecho Internacional de los Derechos Humanos, como lo es el de la protección especial de las personas vulnerables. 


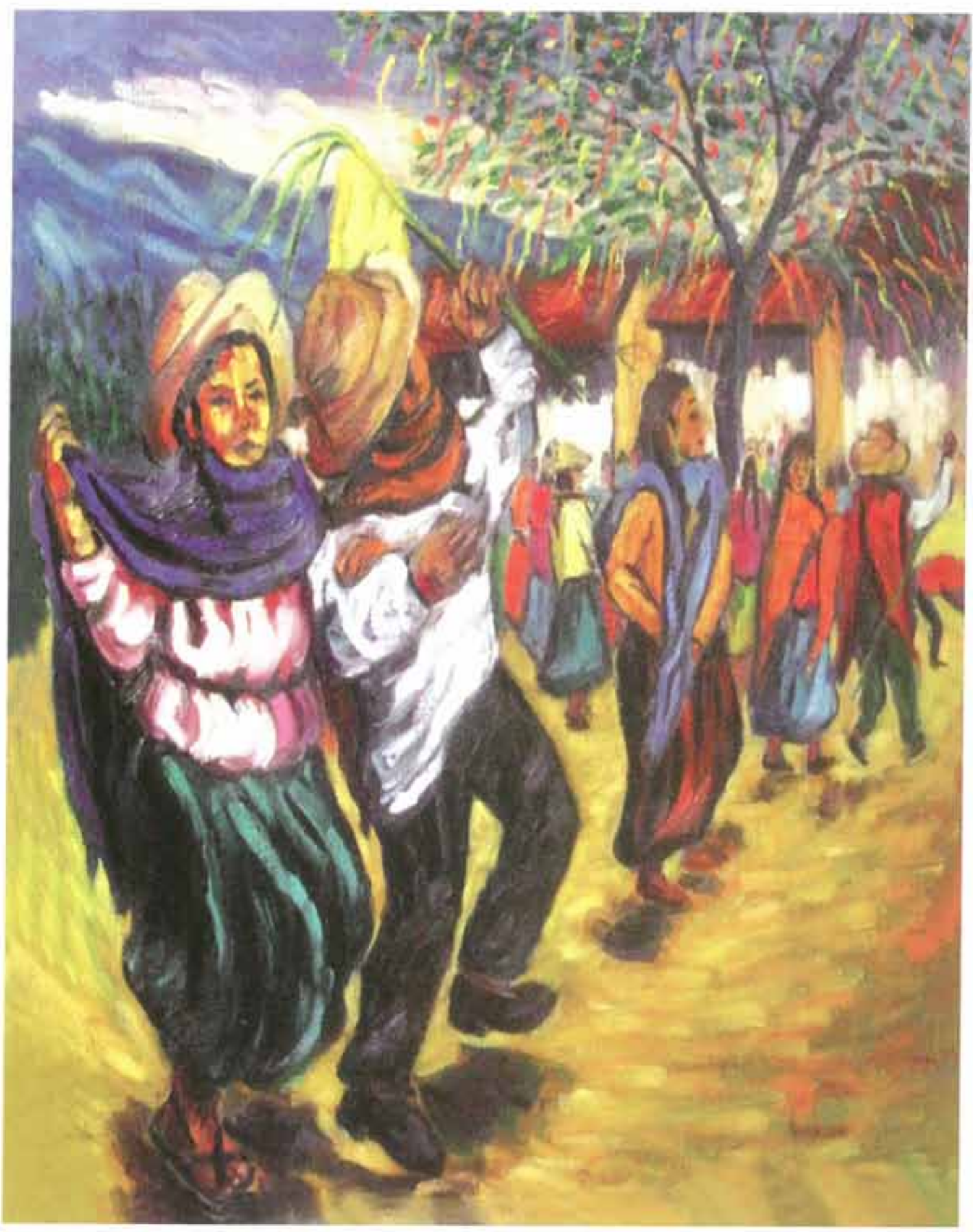

"Humisha" 